\title{
Fabrication of CdSe quantum dots/permutite luminescent materials
}

\author{
MEIHUA YU ${ }^{1}$ and YILIN WANG ${ }^{1,2, *}$ \\ ${ }^{1}$ Ministry-Province Jointly-Constructed Cultivation Base for State Key Laboratory of Processing for \\ Non-ferrous Metal and Featured Materials, Guangxi Zhuang Autonomous Region, \\ Guangxi University, Nanning 530004, China \\ ${ }^{2}$ School of Chemistry and Chemical Engineering, Guangxi University, Nanning 530004, China
}

MS received 12 December 2014; accepted 16 April 2015

\begin{abstract}
Permutite incorporating CdSe in mesopores has been prepared with a simple route. Firstly, mercaptosuccinic acid-capped CdSe quantum dots (QDs) were prepared in aqueous solution by using $\mathrm{SeO}_{2}$ as selenium source and $\mathrm{NaBH}_{4}$ as reductant. Secondly, the commercial permutite was treated with acetic acid to induce a partial dealumnization, which can introduce a large number of intracrystal mesopores, and the CdSe QDs were successfully incorporated in the mesopores with the wet impregnation method. Photoluminescence spectra, X-ray diffraction and scanning electron microscopy were used for the characterization of samples. The spectra analyses results showed that the illuminant colour of QDs/permutite powder was similar to the corresponding QDs colloid. X-ray diffraction measurements indicated that the $\left(\begin{array}{lll}1 & 0 & 1\end{array}\right)$ diffraction peak at $2 \theta=27^{\circ}$ for QDs/permutite powder was the same as the raw permutite, and the energy-dispersive $\mathrm{X}$-ray spectra demonstrated that $\mathrm{Cd}$ and Se elements existed in the CdSe QDs/permutite powder.
\end{abstract}

Keywords. Nanocrystalline materials; composite materials; luminescence; permutite.

\section{Introduction}

Over the past few decades, quantum dots (QDs) have been of great interest for both fundamental research and technical applications ${ }^{1-4}$ because of their unique optical and electrical properties. In most of the applications, including chemical analysis and biological imaging, QDs have been used in a suspension colloidal form. However, in some fields such as photocatalysis and light-emitting diode, QDs are required in a solid powder form. Although many approaches have been developed for the preparation of QDs in organic and aqueous solutions, ${ }^{5,6}$ it is difficult to obtain large amount of QD's powder. Nowadays, two successful routes have been reported for resolving this problem, one is the preparation of QD composites. For example, montmorillonite clay has been used as the host media for CdTe QDs to prepare luminescent QDs/clay powder by freeze drying. ${ }^{7}$ And another is the growth of QDs inside the channels of a porous matrix such as zeolites, which are crystalline alumino-silicates with cages and channels that can be used as constrained systems for the preparation of QDs such as $\mathrm{CdS}, \mathrm{MnS}$ and $\mathrm{ZnS},{ }^{8,9}$ but the luminescent properties were not studied. In recent times, the use of zeolites as molecular scaffolds for the fabrication of luminescent materials by incorporating transition metals has also been explored. ${ }^{10-12}$ Permutite is a kind of synthesized alumino-silicates

*Author for correspondence (theanalyst @ 163.com) composed of many great micropores with uniform open windows in the framework, which can be extensively used as adsorbent and heterogeneous catalyst in industry. ${ }^{13}$ In the present work, mercaptosuccinic acid (MSA)capped CdSe QDs were first prepared in aqueous solution by using $\mathrm{SeO}_{2}$ as selenium source and $\mathrm{NaBH}_{4}$ as reductant. Then the mesoporous material permutite was used as the host media for CdSe QDs to obtain QDs/permutite luminescent materials.

\section{Experimental}

\subsection{Reagents and materials}

Mercaptosuccinic acid (98\%, Aladdin Chemistry Co. Ltd.), $\mathrm{CdCl}_{2} \cdot 2.5 \mathrm{H}_{2} \mathrm{O}$ (99\%, Tianjin Damao Chemical Reagent Factory), $\mathrm{SeO}_{2}$ (99.9\%, Aladdin Chemistry Co. Ltd.) and $\mathrm{NaBH}_{4}(96 \%$, Shanghai JingHua Scientific \& Technological Research Institute) were used for the preparation of CdSe. Commercial permutite was purchased from Sinopharm Chemical Reagent Co. Ltd. All chemicals were used as-received without further purification. Double deionized water was used throughout the experiment.

\subsection{Preparation procedures}

The synthesis of CdSe QDs is described as follows: under vigorous stirring, $0.4567 \mathrm{~g}(2 \mathrm{mmol}) \mathrm{CdCl}_{2} \cdot 2.5 \mathrm{H}_{2} \mathrm{O}$ and 
$0.4207 \mathrm{~g}$ (2.8 mmol) MSA were mixed in $100 \mathrm{ml}$ of deionized water in a $250-\mathrm{ml}$ three-neck flask. $\mathrm{NaOH}$ solution $\left(1.0 \mathrm{~mol} \mathrm{l}^{-1}\right)$ was used to adjust the $\mathrm{pH}$ of the mixture to 11.8. After that, $0.05 \mathrm{~g} \mathrm{NaBH}_{4}$ and $0.0222 \mathrm{~g}$ $(0.2 \mathrm{mmol}) \quad \mathrm{SeO}_{2}$ was added successively into the above solution. The resulting mixture solution was heated to $100^{\circ} \mathrm{C}$ under open-air conditions and refluxed at different times for controlling the size of the $\mathrm{CdSe}$ QDs.

2.2a Pretreatment of the permutite: Permutite with mesh sieve 40-60 of $10 \mathrm{~g}$ was weighed, then washed and stirred using warm acetic acid of $3 \%$ with 10 -fold of the permutite's volume twice, each time took $10 \mathrm{~min}$. After that, the permutite was washed and stirred using warm potassium chloride of $25 \%$ with 5 -fold of permutite's volume for $15 \mathrm{~min}$. As the same manner, warm acetic acid of $3 \%$ was used to wash the permutite $10 \mathrm{~min}$, finally, distilled water was employed to the permutite until no chloride left. The pretreated permutite was dried in air.

2.2b Preparation of QDs/permutite composites: Two grams of pretreated permutite was taken in a round bottom flask, to which $50 \mathrm{ml}$ of QD's colloid was added. The mixture was stirred, sealed and maintained at room temperature for $24 \mathrm{~h}$. Then the product was separated and purified by series of centrifugation and ultrasonic redispersion in water. Finally, the precipitate was dried in air at room temperature. The above-mentioned preparation procedure is illustrated in scheme 1 .

\subsection{Characterization}

The absorption and photoluminescence (PL) spectra were measured using a UV-2102 spectrometer and a RF-5301 fluorescence spectrometer, respectively. Transmission electron microscopy (TEM) imaging was implemented by a JEM-3010 electron microscope at $300 \mathrm{kV}$. X-ray powder diffraction (XRD) measurements were performed using a D/MAX 2500V diffractometer equipped with $\mathrm{CuK} \alpha$ radiation $(\lambda=0.15406 \mathrm{~nm})$. Scanning electron microscopy
(SEM) was carried out on SU8000 with an operating voltage $10 \mathrm{kV}$.

\section{Results and discussion}

\subsection{Preparation of CdSe QDs using $\mathrm{SeO}_{2}$ as selenium source}

The aqueous synthesis of QDs is based on the Ostwald ripening phenomenon, and the formation of QDs in solution involves two stages: nucleation and growth. In this synthesis process, the formation of CdSe QDs can be illustrated as scheme 2: first, $\mathrm{Cd}^{2+}-\mathrm{MSA}$ complexes were formed under basic condition. Then $\mathrm{NaBH}_{4}$ would react with sodium selenite $\left(\mathrm{Na}_{2} \mathrm{SeO}_{3}\right)$, obtained from selenium dioxide $\left(\mathrm{SeO}_{2}\right)$, to form $\mathrm{Se}^{2-}$ ions that combine with $\mathrm{Cd}^{2+}-\mathrm{MSA}$ complexes to give $\mathrm{CdSe}$ nuclei. With the CdSe nuclei growing under refluxing, the CdSe QDs were formed at last.

The normalized UV-vis absorption and PL spectra of CdSe QDs prepared at different reaction times are shown in figure 1. As can be seen, all samples show a wellresolved absorption maximum of the first electronic transition. With time, there is a gradual increase in the absorption edge towards lower energy, implying the increase of CdSe nanoparticle size. The particle size is estimated using a simple equation ${ }^{14}$ proposed for spherically shaped particle

$$
\Delta E_{\mathrm{g}}=\frac{h^{2}}{8 a^{2}}\left(\frac{1}{m_{\mathrm{e}}}+\frac{1}{m_{\mathrm{h}}}\right),
$$

where $\Delta E_{\mathrm{g}}=\left(E_{\mathrm{g}}^{\mathrm{n}}-E_{\mathrm{g}}^{\mathrm{b}}\right)$ is the difference between the bandgaps of nanoparticles $\left(E_{\mathrm{g}}^{\mathrm{n}}\right)$ and the bulk $\left(E_{\mathrm{g}}^{\mathrm{b}}\right), h$ Planck's constant, $\alpha$ the diameter of a particle and $m_{\mathrm{e}}$ and $m_{\mathrm{h}}$ are the effective masses of electrons and holes, respectively. In this paper, $m_{\mathrm{e}}=0.13 m_{0}, m_{\mathrm{h}}=0.44 m_{0}, m_{0}=9.1095 \times$ $10^{-31} \mathrm{~kg}$ and $E_{\mathrm{g}}^{\mathrm{b}}=1.74 \mathrm{eV}$ were used for the calculation of the particle size. The absorption edges (dashed line) at different refluxed times were $540 \mathrm{~nm}(2.30 \mathrm{eV}), 551 \mathrm{~nm}$ $(2.25 \mathrm{eV}), 560 \mathrm{~nm}(2.21 \mathrm{eV})$ and $568 \mathrm{~nm}(2.18 \mathrm{eV})$, respectively. Compared with CdSe bulk material $(716 \mathrm{~nm})$, the absorption edges of CdSe QDs have significant blue

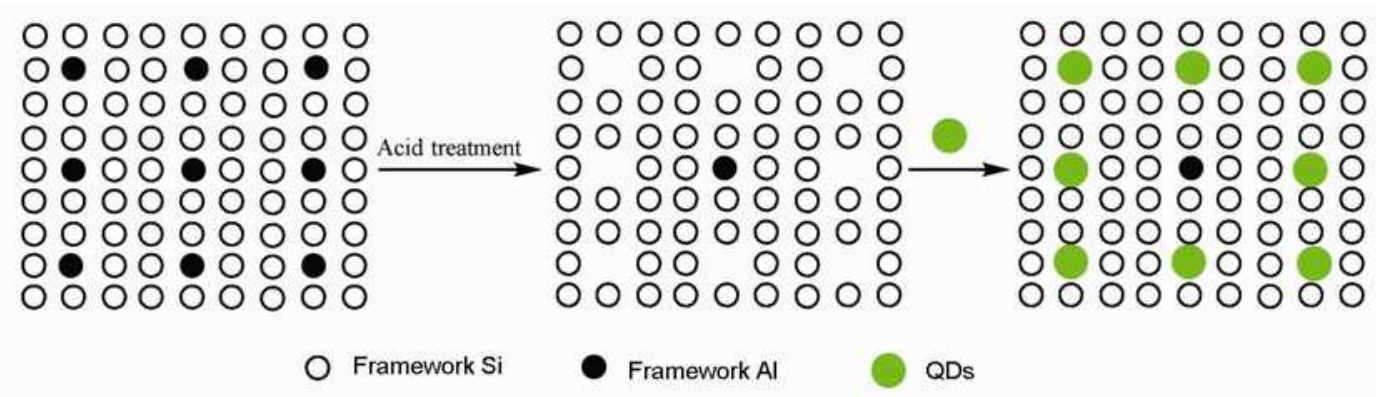

Scheme 1. Schematic illustration of the preparation of CdTe/permutite composites. 
shift, which shows obvious quantum confinement effect. According to equation (1), the diameter was estimated to 2.6, 2.7, 2.8 and $2.9 \mathrm{~nm}$, respectively. The particle size increases from 2.6 to $2.9 \mathrm{~nm}$ over a period of $9 \mathrm{~h}$, which indicate that the growth kinetics is slow. This is due to the fact that the preparation was carried out at low temperature, which is an important aspect of the growth of QDs.

As described in figure 1 (solid line), the PL bands of the obtained CdSe QDs are located close to the absorption thresholds (so-called band-edge or 'excitonic' PL) and are sufficiently narrow (full-width at half-maximum, FWHM, is about $35 \mathrm{~nm}$, almost comparable to the CdSe QDs prepared by an organic synthesis. ${ }^{15}$ ) This is probably a result of the strong capping of $\mathrm{Cd}^{2+}$ ions with MSA molecules (one $-\mathrm{SH}$ and two - $\mathrm{COOH}$ groups), which is an important aspect of the processing of QDs with narrower size distribution. The reason for the generation of bandgap emission is a result of the fact that MSA is an effective passivating agent as compared to other thiols and hence the dangling bonds or traps on the particles surface can be effectively removed. The position of the PL maximum of the smallest $(2.6 \mathrm{~nm}) \mathrm{CdSe}$ QDs is located at $531 \mathrm{~nm}$ (green emission), whereas the largest $(2.9 \mathrm{~nm})$ CdSe QDs obtained emit in yellow-green with a PL maximum at $556 \mathrm{~nm}$. Furthermore, these QDs were very stable in the dark under ambient conditions. After being

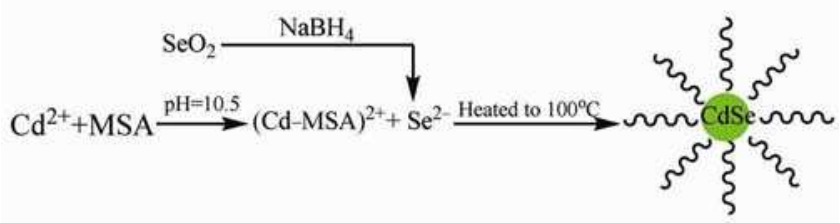

Scheme 2. Schematic illustration of the formation of CdSe QDs.

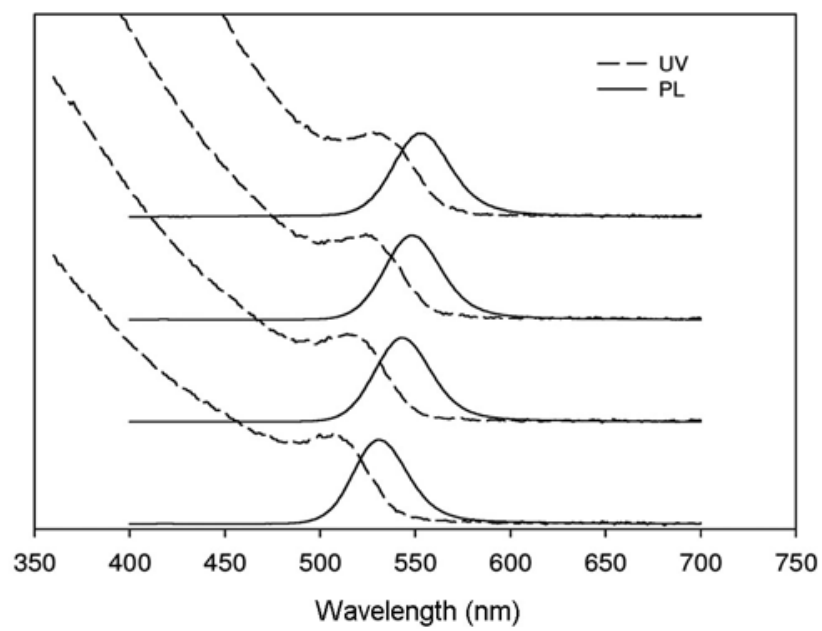

Figure 1. Temporal evolution of UV-vis absorption (dashed line) and PL (solid line) spectra of CdSe QDs. kept for 6 months, their absorption and PL spectra almost had no change, and no obvious precipitations were observed.

The morphological characteristics of the CdSe QDs were carried out by TEM and high-resolution transmission electron microscopy (HRTEM). As seen in figure $2 \mathrm{a}$, the particles are spherical in shape and show good homogeneity in the particle size distribution. The presence of clear lattice planes in HRTEM image (figure 2b) confirms that the QDs have good crystallinity, which is further supported by the selected area electron diffraction (SAED) pattern (figure 2c). In addition, the average CdSe size is about $3.0 \mathrm{~nm}$ and a latticed spacing of $0.351 \mathrm{~nm}$ agrees well with the (111) plane of CdSe (JCPDS190191).

\subsection{Preparation of CdSe/permutite luminescent materials}

The combination of QDs and permutite was carried out by an impregnation method, and the CdSe QDs with $\lambda_{\mathrm{em}}$ at $543 \mathrm{~nm}$ was used for the preparation of QDs/permutite luminescent materials. Figure 3 presents the images of permutite and CdSe QDs/permutite powder in day-light (a, b) and under UV-light (c, d). It can be seen that the permutite was a white powder (figure $3 \mathrm{a}$ ) in day-light and no fluorescence was observed (figure 3c) under UV-light, while the QDs/permutite composites was pale yellow powder (figure 3b), which emitted green fluorescence (figure 3d). These results confirm that the CdSe QDs had been incorporated to the permutite molecular scaffolds.

The emission wavelength of the QDs/permutite composites was $543 \mathrm{~nm}$ as shown in figure 4, which was same as the pure CdSe QD's colloid. However, for the QD's powder, the solid PL wavelength of CdSe QDs was $551 \mathrm{~nm}$, which exhibited a red-shift of $8 \mathrm{~nm}$ after the centrifugation and drying. In the systems where colloidal

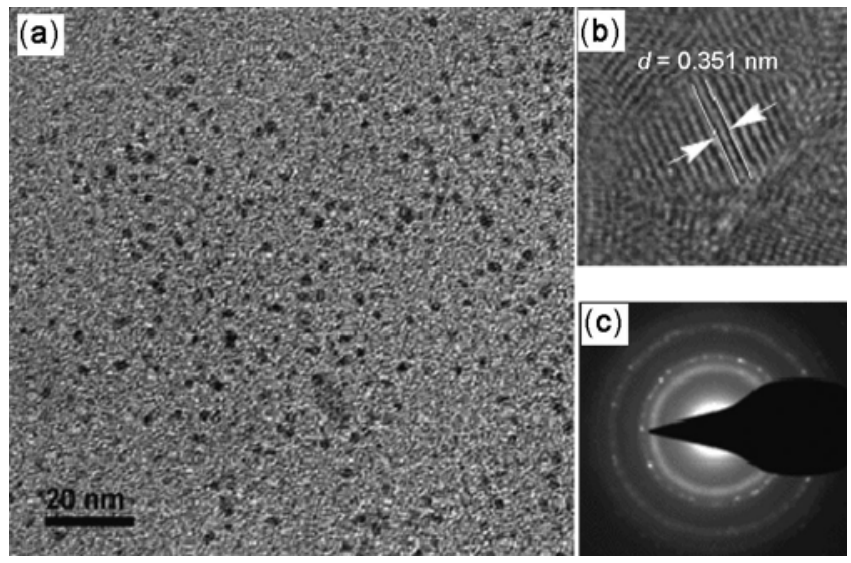

Figure 2. (a) TEM image, (b) HRTEM image and (c) selected area electron diffraction (SAED) pattern of the as-synthesized CdSe QDs. 


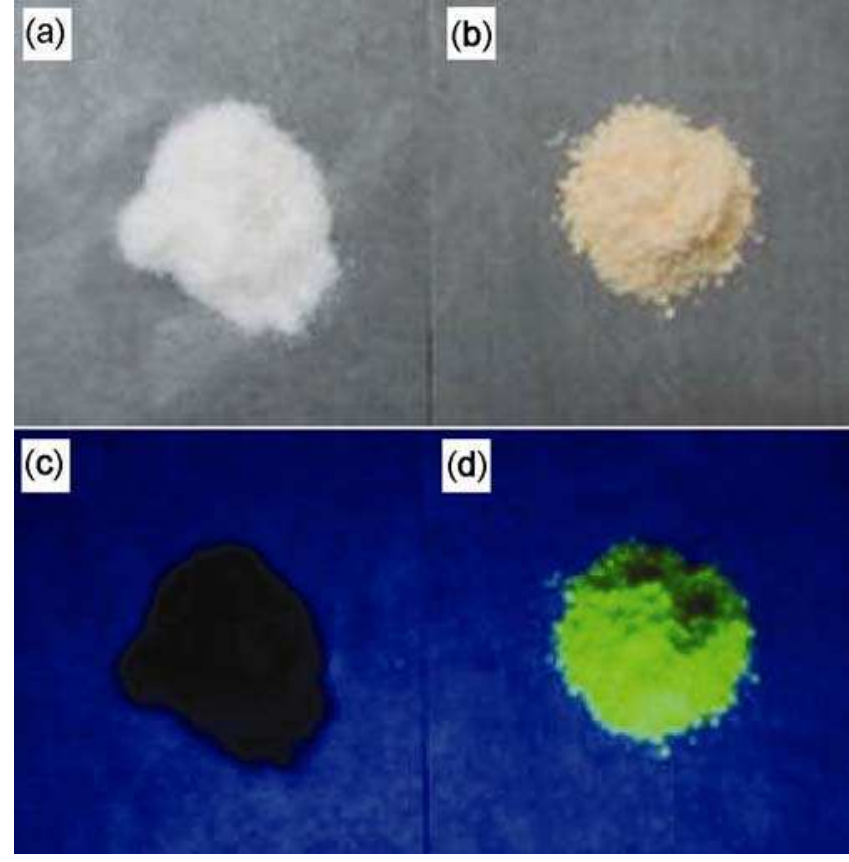

Figure 3. Images of permutite and QDs/permutite composites in $(\mathbf{a}, \mathbf{b})$ day-light and $(\mathbf{c}, \mathbf{d})$ under UV-light.

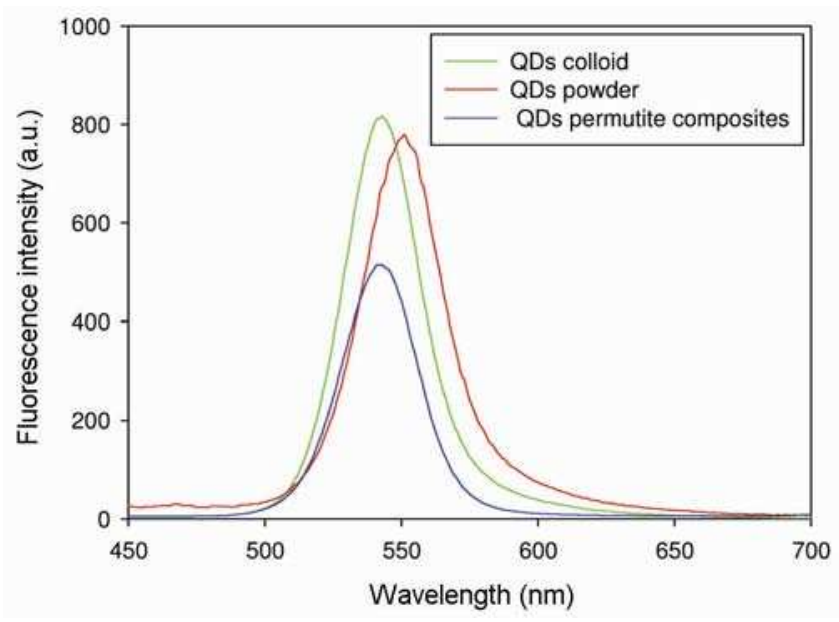

Figure 4. The photoluminescence spectra of QDs colloid, QDs powder and QDs/permutite composites.

aggregates were formed, QDs exhibited red-shifting as the aggregate size increased. These results indicate that the QDs in the QDs/permutite composites preparation were well-dispersed without aggregation, so the PL spectra of the composites did not change compared to the pure QD's colloid. However, for the QDs that were centrifuged and dried, the sample clearly underwent a red-shift, which means that aggregation occurred during the process.

The diffraction peak at $26^{\circ}, 43^{\circ}$ and $51^{\circ}(2 \theta)$ in figure 5 for $\mathrm{CdSe}$ QDs can be assigned to that of CdSe QDs with cubic zinc blende structure. It is well known that if the metal oxides are fully located in the channels of

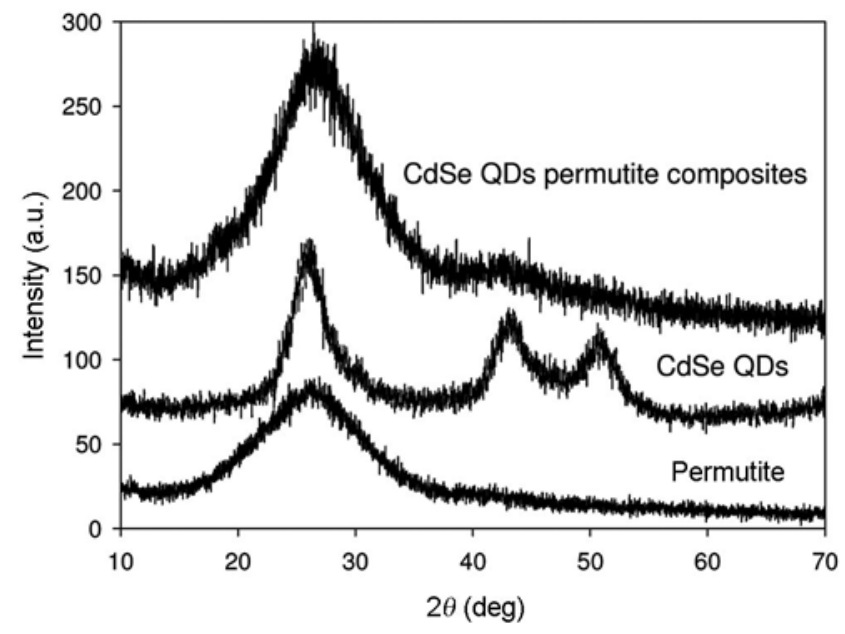

Figure 5. XRD patterns of permutite, CdSe QDs and CdSe QDs/permutite composites.
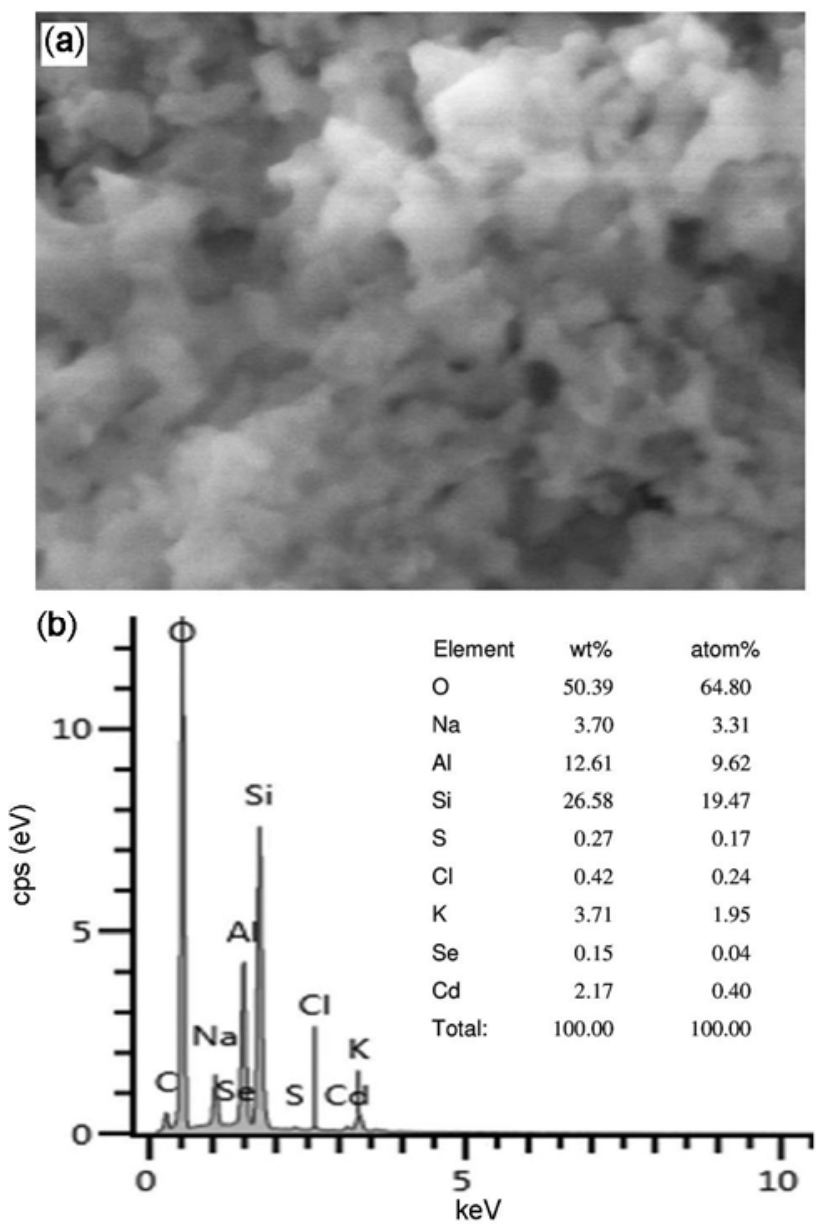

Figure 6. (a) SEM photograph and (b) EDX spectra of CdSe QDs/permutite composites.

permutite or mesoporous materials, the corresponding diffraction peaks nearly disappear because of the shielding effects of surrounding hosts. ${ }^{16}$ Only weak diffraction 
peak at $43^{\circ}(2 \theta)$ for CdSe QDs appeared in XRD pattern of $\mathrm{CdSe} \mathrm{QDs} /$ permutite composites, implying that the CdSe QDs were probably located in the micropores or mesopores of the permutite. According to the empirical equation (1), the calculated CdSe QDs diameter is about $2.7 \mathrm{~nm}$, so it is impossible for CdSe to enter the permutite micropores with pore size lower than $1 \mathrm{~nm}$, which are supposed to be located in the mesopores introduced by pretreatment. The broader diffraction peak at $2 \theta=27^{\circ}$ for permutite also appeared in XRD pattern of CdSe QDs/ permutite composites, indicating that the preparation of CdSe QDs/permutite composites did not change the permutite structure.

The microstructure of the QDs/permutite composites sample has been studied by SEM, as revealed in figure 6a. The porous structure of the QDs/permutite composites was a cauliflower-like material. The composition of QDs/permutite composites was investigated by the energydispersive X-ray (EDX) spectra technique. From figure $6 \mathrm{~b}$, the characteristic peaks of $\mathrm{K}, \mathrm{Na}, \mathrm{Al}, \mathrm{Si}, \mathrm{S}, \mathrm{Cd}$ and $\mathrm{Se}$, which indicate the components of the $\mathrm{CdSe}$ QDs/permutite composites can be observed. Among these elements, K, Na, Al and $\mathrm{Si}$ were from the permutite, while $\mathrm{Cd}$, Se and $\mathrm{S}$ were from the CdSe QDs. These results suggested that the CdSe QDs existed in the permutite cauliflowers and were dispersed in the permutite matrix.

\section{Conclusions}

Mercaptosuccinic acid-capped CdSe QDs were prepared in aqueous solution by using $\mathrm{SeO}_{2}$ as selenium source and $\mathrm{NaBH}_{4}$ as reductant. A facile method has been developed to prepare CdSe QDs/permutite composites. The microstructure, composition and luminescent property of the obtained samples were investigated by XRD, SEM and PL spectra. After being incorporated to permutite, the PL spectra of the QDs almost had no change. As a kind of novel powder material, CdSe QDs/permutite composites are promising candidates to use as photocatalysis, lightemitting diode and so on.

\section{Acknowledgement}

This work was supported by the Ministry-Province Jointlyconstructed Cultivation Base for State Key Laboratory of Processing for Non-ferrous Metal and Featured Materials, Guangxi Zhuang Autonomous Region (GXKFJ12-18).

\section{References}

1. Zhang K, Guo J K, Niea J J, Du B Y and Xu D J 2014 Sens. Actuators B 190279

2. Hu X F, Zhang X L and Jin W R 2013 Electrochim. Acta 94367

3. Xuan T T, Wang X J, Zhu G, Li H L, Pan L K and Sun Z 2013 J. Alloys Compd. 558105

4. Xu T, Zou F, Yu Y and Zhi J F 2013 Mater. Lett. 968

5. Bera S, Singh S B and Ray S K 2012 J. Solid State Chem. 18975

6. Zhao Q, Rong X L, Ma H B and Tao G H 2013 J. Mater. Sci. 482135

7. Cao Y C 2012 J. Colloid Interface Sci. 368139

8. Nezamzadeh-Ejhieh A and Banan Z A 2011 Desalination 279146

9. Kim H S, Jeong N C and Yoon K B $2011 \mathrm{~J}$. Am. Chem. Soc. 1331642

10. Coutino-Gonzalez E, Roeffaers M B J, Dieu B, Cremer G D, Leyre S, Hanselaer P, Fyen W, Sels B and Hofkens J 2013 J. Phys. Chem. C 1176998

11. Guerrero-Martinez A, Fibikar S, Pastoriza-Santos I, LizMarzan L M and Cola L D 2009 Angew. Chem. Int. Ed. 48 1266

12. Tsotsalas M, Busby M, Gianolio E, Aime S and Cola L D 2008 Chem. Mater. 205888

13. Tao Y S, Kanoh H, Abrams L and Kaneko K 2006 Chem. Rev. 106896

14. Kalasad M N, Rabinal M K and Mulimani B G 2009 Langmuir 2512729

15. Wang L, Sun X D and Liu W J 2010 Mater. Chem. Phys. 12054

16. Cheng X W, Meng Q Y, Chen J Y and Long Y C 2012 Microporous Mesoporous Mater. 153198 